\title{
Potassium for better crop production and quality
}

\author{
Ismail Cakmak
}

Received: 25 July 2010 /Accepted: 9 August 2010 / Published online: 27 August 2010

(C) Springer Science+Business Media B.V. 2010

Increasing crop production while improving quality remains an important goal, particularly in the developing world. Significant increases in food prices and growing economic crises have a major impact on nutritional status of human populations and exacerbate global malnutrition. These developments make nutrient security together with food security a key global challenge.

Among many factors, an adequate and well balanced nutrition with mineral nutrients is a fundamental issue in achieving a high crop production and a better quality in practical agriculture. Of the mineral nutrients, imbalanced nutrition with potassium $(\mathrm{K})$ is well known and becoming an important constraint to crop production in the developing countries. Very low rates of potash fertilizer application in agricultural production in India and other developing countries lead to rapid depletion of $\mathrm{K}$ in the soil. Depletion of plant-available $\mathrm{K}$ in soils results in a variety of negative impacts, including preventing optimum utilization of applied nitrogen and phosphorus fertilizers, decreasing farmers' income, threatens the yields of the cropping systems (e.g., wheat-rice cropping systems)

Responsible Editor: Hans Lambers.

I. Cakmak $(\bowtie)$

Faculty of Engineering and Natural Sciences,

Sabanci University,

34956 Istanbul, Turkey

e-mail: cakmak@sabanciuniv.edu and hence jeopardizes the future food and nutrient security. Indian growers and their advisors need to adopt advanced tools for potash fertilizer applications and updated $\mathrm{K}$ recommendations by considering nutrient management practices based on the latest scientific findings. Currently, there is increasing evidence for the diverse functions of $\mathrm{K}$ from the molecular level to field performance. The role of $\mathrm{K}$ in stress signaling is becoming an important topic (Amtmann et al. 2008; Wang and $\mathrm{Wu} 2010$ ) that needs to be addressed increasingly in future research by molecular biologists, plant physiologists and agronomists. The stressmitigating role of $\mathrm{K}$ is another role in plants, particularly under drought, salinity, and upon pathogenic infection (Cakmak 2005; Amtmann et al. 2008). An adequate K nutrition is also of great importance for the composition of harvested products and the quality of diet. In addition, impaired nutrient management and related nutrient inputoutput imbalances, especially with $\mathrm{K}$, may represent a serious issue in forest nutrition and wood production (Ache et al. 2010).

The Potassium Symposium entitled "Potassium Role and Benefits in Improving Nutrient Management for Food Production, Quality and Reduced Environmental Damages" was organized in order to discuss and analyze the issues described above. The papers given in this Special Issue focus on the role of potassium and other mineral nutrients in cropping systems, nutrient-use efficiency, food production and quality, forest nutrition, and climatic changes. This Potassium Symposium provided an excellent opportunity 
for nearly 220 scientists to present their work, and collect information about the new research findings and to establish international networks and collaboration.

The conference featured 32 oral presentations, which were made by distinguished keynote speakers and addressed the following topics:

- Nutrient management to meet challenges of food security

- Nutrient-use efficiency and potassium

- Role of potassium and mineral nutrition in alleviation of stress

- Production and quality of agricultural products and impacts on the environment and humans

- Spatial variability of soil properties and Site Specific Nutrient Management (SSNM)

- The role of extension in increasing agricultural productivity

- Nutrient mining and input-output balances

- Future research on potassium in agriculture

This symposium was held in Bhubaneswar, Orissa, India (5-7 November, 2009) and jointly organized by the International Potassium Institute (IPI), International Plant Nutrition Institute (IPNI) and the Orissa University of Agriculture and Technology (OUAT). This scientific event is the third in the series of two large similar symposia organized in India in 2001 (New Delhi) and in 2006 (Ludhiana). The proceedings of the symposium will be published jointly by IPI, IPNI and OUAT, including all oral and poster presentations.

The organizers thank all participants and sponsors for their support, and Plant and Soil for devoting a part of this issue to selected papers from this Potassium Symposium.

\section{References}

Ache P, Fromm J, Hedrich R (2010) Potassium-dependent wood formation in poplar: seasonal aspects and environmental limitations. Plant Biol 12:259-267

Amtmann A, Troufflard S, Armengaud P (2008) The effect of potassium nutrition on pest and disease resistance in plants. Physiol Plant 133:682-691

Cakmak I (2005) The role of potassium in alleviating detrimental effects of abiotic stresses in plants. J Plant Nutr Soil Sci 168:521-530

Wang Y, Wu W-H (2010) Plant sensing and signaling in response to $\mathrm{K}^{+}$deficiency. Mol Plant 3:280-287 